\title{
Response of five-phase synchronous reluctance motor with direct torque control technique
}

\author{
Namariq Abdulameer Ameen", Ali Kadhim Abdulabbas and Habeeb Jaber Nekad \\ Department of Electrical Engineering, University of Basrah, Basrah, Iraq
}

Received:21-July-2021; Revised: 18-November-2021; Accepted: 19-November-2021

(C2021 Namariq Abdulameer Ameen et al. This is an open access article distributed under the Creative Commons Attribution (CC BY) License, which permits unrestricted use, distribution, and reproduction in any medium, provided the original work is properly cited.

\begin{abstract}
Multiphase ac machine drives are now considered for various applications as they afford numerous benefits over their three-phase counterparts. As a result, using five-phase machines in electric drive systems is becoming more common in many industries. This paper presents a five-phase Synchronous Reluctance Motor (SynRM) design with a Direct Torque Control (DTC) strategy to establish the motor's dynamic simulation and reduce torque ripple resulting from the anisotropic structure of rotor to be \pm 5 and to control the motor speed at acceleration and deceleration. A five-phase voltage source inverter pulses are generated using a specific DTC Space Vector Modulation (DTC-SVM) technique. There are two look-up tables derived from stator flux linkage and electromagnetic torque control by using proper voltage space vectors. The technique used in this paper is considered a fast and straightforward method comparable to the other techniques. This paper also includes a control block schematic and a description of manners performance under various load situations and varied reference speeds at the transient and steady-state conditions. Lastly, simulation results achieved via Matlab/Simulink software show that it was a perfect control system because the motor's real speed value strictly follows the reference speed, and all results are conventional and regular.
\end{abstract}

\section{Keywords}

Synchronous reluctance motor, Reluctance torque, Direct torque control and Electric drive systems.

\section{Introduction}

In neoteric times, the Synchronous Reluctance Motor (SynRM) has aroused the curiosity of several scientists as a viable induction drive replacement, and it's considered a viable option for a variety of variable-speed drive systems [1-3]. The stator structure of SynRM and the Induction Motor (IM) is identical, but there are no field windings in the rotor, resulting in lower losses and improved competence [4]. SynRM is inexpensive from permanent magnet motors because it does not involve magnets [5]. SynRM has many benefits over induction motors, including a more straightforward, robust build, ease of maintenance, lower production costs, a quiet moment of inertia, and better torque density [2,6]. The SynRM is structurally simpler than Switched Reluctance Motor (SRM) as it has a rotor being salient only. In contrast, SRM has a structure of double salient, and it is superior to SRM in torque ripple point of view $[2,7,8]$.

*Author for correspondence

1454
There is a main drawback in SynRM, it has some ripples in the developed torque, but such problems may be solved by adjusting SynRM's model parameters or suggesting a relevant control strategy [4]. Moreover, more phases of SynRM can reduce the not coveted torque ripple $[9,10]$.

Recently, with the evolution of contemporary power electronics, multiphase SynRM has been a popular alternative. As a result, the five-phase machine has attracted a lot of interest [11]. For a multitude of purposes, high phase number drives are frequently preferred over three-phase drives, including high torque density, greater efficiency, excellent fault toleration, the amplitude is diminishing in torque pulsations with increased frequency, lessened harmonic currents in the rotor, reduced current per phase, phase voltage is nearly stable, and proper DC link current harmonics [2, 4, 12].

Multiphase electrical machine developments have lately been performed in areas that require high believability, such as hybrid automobiles, ship 
impulsion, aircraft equipment, and high-power purposes $[5,13,14]$.

In this paper, the five-phase SynRM is modeled using the reference frame concept. In addition, the fundamental harmonic of the spatial field is exclusively used to generate motor torque. The best easy Direct Torque Control method is implemented using a specific Space Vector Modulation (DTCSVM) technique via Matlab/Simulink program. Accordingly, the torque and flux are regulated in the stationary reference frame by hysteresis controllers. Using a simple look-up table for command voltages application, the generated electromagnetic torque and flux can be regulated quickly and provide a high dynamic control strategy. This paper is intended to obtain the consequences by the DTC technique; the electromagnetic torque and flux are directly controlled without decoupled, there is no need for current controllers [15]. The speed with various load values and conditions, acceleration \& deceleration, and forward or reverse modes will be explained. As a result, the motor is entirely controlled, and the consequences demonstrate that this method is viable. This work proposes a combined torque regulator based Direct Torque Control (DTC) scheme to maintain the benefits of regular DTC while improving torque tracking performance. For torque control optimization, the composite torque regulator combines two additional variable hysteresis bands with two constant hysteresis bandsThe constant hysteresis bands are incorporated to maintain the fast dynamic response of classic DTC via spatial DTC space vector modulation (DTC-SVM) and how to use the MATLAB/SIMULINK program to implement the DTC method, while the variable hysteresis bands are employed to improve torque tracking precision under steady state Two elements are identified and investigated in this study impairs torque tracking in a traditional DTC strategy: The first is that the mean torque will deviate significantly from the reference torque given the disparity in torque increasing and decreasing rates. The second is that adding one sampling rate to the delay time leads torque tracking to deteriorate further. The effects of torque variation and time delay on torque ripple are eliminated when the proposed composite torque regulator is used. The suggested composite torque regulator-based DTC method, retains the advantages of traditional DTC schemes, such as low switching frequency, fast dynamic response, simple construction, and motor parameter independent. The DTC technique, which is based on a compound torque regulator, can enhance torque monitoring in both steady and dynamic processes. The following is how the rest of the paper is structured: section 2 has the literature review discussion; section 3 covers the mathematical modeling and transformations of a fivephase SynRM motor. Furthermore, the characteristics of torque tracking under various speeds and loads are carefully investigated. Two variable hysteresis bands are paired with constant hysteresis bands in the torque regulator to optimize torque control. The conventional switching table-based DTC is presented for analysis and all the results are in section 4. In section 5, discussion is specified to explain the performance of the DTC with composite torque regulator and the limitations. Finally, the conclusions and future work are shown in section 6 .

\section{Literature review}

In previous years, the idea of $\mathrm{AC}$ machine drive control techniques, their whole MATLAB/Simulink simulation was designed. There is a lot of intention for energy conserving. By creating effective operation systems for the electrical machines, we may save energy. Furthermore, it has been discovered that altering the speed of motors based on the load has a positive effect. As a result of the variable speed operation, efficiency can be significantly enhanced. The control systems of electric drives such as fieldoriented control FOC, DTC and a five-phase motor drive system are illustrated. These techniques provide advantages for electric machines to have an exceptionally quick and accurate dynamic and steady-state responses. MATLAB/ Simulink is a widely used software that is offered for undergraduate and postgraduate degrees. It is also widely used in industry [16].

Torque ripple reduction, position sensor deletion, and the use of fractional-slot winding arrangements are all priorities. The simulation of PM synchronous machines for both machinery implementation and control. The construction of flux observers, the deletion of location sensors, and model identification are among the issues discussed in [17]. A computerassisted development of synchronous reluctance and internal PM machines is also available. It is investigated whether electromagnetic finite element analysis may be integrated with recommender systems due to its global search algorithms.

Yousefi-Talouki et al. [18] presents a sensor less direct flux vector control method for SynRM drives. Using stator flux oriented reference frame, torque is handled at a constant switching frequency by closed loop management of the stator flux linkage vector 
and the current part in quadrature with it. Backelectromotive force integration is used with pulsating voltage injection around zero speed in a hybrid flux and position monitor. The considerable experimental findings demonstrate the practicality of the suggested strategy for a $2.2-\mathrm{kW}$ synchronous reluctance motor model. It included standstill speed reaction to step and sinusoidal load changes up to 121 percent of rated torque, as well as speed response studies that encompass the flux weakening speed range.

Multiphase motors have several benefits, including increased efficiency, less torque oscillation, and increased reliability. All conceivable switching patterns for a certain switching number and carrier frequency were investigated in [19]. Next, to decrease rms harmonic current, the optimal spatial arrangement of each pattern was calculated, producing Optimal Hybrid Pulse Width Modulation (OHPWM). The chosen strategy reduces total current harmonics deformation by using alternative switching patterns.

An appropriate PWM approach is required to control multi-phase AC drives fed by voltage source inverters (VSIs). The efficiency of a 5-phase induction motor drive using different space vector PWM (SVPWM) algorithms is investigated in [20]. SVPWM switching approaches founded on medium, large, and a mix of medium and large vectors have been proposed, allowing for lower percent THD in output voltages. The suggested approach uses the entire DC bus voltage, and the output response is better than the traditional SVPWM techniques with lower order harmonics. The results were noticed about harmonic contents contained in the output voltage waveform when the 5-phase VSI fed IM drive was evaluated with several switching approaches by MATLAB/SIMULINK software.

Rangari et al. [21] analyze and contrast pulse width modulation systems for two level five-phase VSI. Just two large vectors and four large and medium vectors are employed in a five-phase VSI (SVPWM). Current space vector pulse width modulation (SVPWM) methods work by selecting ( $\mathrm{n}$ - 1) active space vectors (for odd phase numbers) in a given interval to produce either sinusoidal voltage or sinusoidal basic voltage with a small quantity of additional harmonic components.

Based on mathematical modeling, the dynamic simulation of a five-phase SynRM fed by a fivephase VSI. The pulses for the inverter are generated using the Sinusoidal Pulse Width Modulation (SPWM) approach. For simplify and to avoid the angular reliance of the inductances, the reference frame theory was employed to modify five-phase SynRM voltage equations. The torque is then calculated in terms of phase currents to use the wellknown magnetic co-energy formula [22].

Also, a five-phase PMSM mathematical modeling and a simulation of the DTC method were created. The five-phase PM motor may be well managed by simulating. However, there is a significant torque ripple. Therefore, a new space voltage vector section table was established, to decrease the torque ripples in [23]. It is possible to obtain distinct profiles of each physical object by changing the flux differential hysteresis. Its flaw is that the sector split is fundamental, resulting in relatively significant torque ripples and a minimal influence on efficiency.

Hybrid fuzzy-based matching recommendation algorithm and collaborative sequential map filtering algorithm are two upgraded strategies proposed in [24]. This proposed methodology proposes a novel mechanism for assisting users in accessing learning resources, both individually and collaboratively. To assess and eliminate harmonic activity in the fivephase inverter, a low-pass filter is used to develop and study the five-phase inverter. The centrifugal pump, which demands a high power density, is driven by a SynRM. Using the motor's dynamic equations, a mathematical model of SynRM is created. The FOC control technique is examined, and its performance when flux and current are measured along direct and quadrature axes.

In this paper, a digital controlled system for fivephase SynRM model was implemented using MATLAB/Simulink software. Then a control algorithm for DTC technique was developed .The control algorithm was implemented into a five-phase voltage source inverter design to feed the motor with five-phase controlled voltages. Simulation results were typical and verified the effectiveness of the designed digital controlled five-phase inverter with specific SVM-DTC.

\section{Methods}

Figure 1 shows a prototype scheme for a five-phase SynRM with a rotor with a salient pole shape. There is an angle of $72^{\circ}$ electrical degree between any two adjacent phases [17]. $g_{a}$ represents the minimum air gap interval and $g_{b}$ represents the biggest air gap interval. The ratio between the maximum airgap to 
minimum airgap called the saliency ratio $\frac{g_{b}}{g_{a}}$ which is affected by the torque density. The angle $\theta$ represents the rotor position, and it is the angle between the qaxis of stator and rotor.

Iron saturation is ignored, and only the first component flux will be considered. The following equations are in natural reference frame represented by matrix form [2].

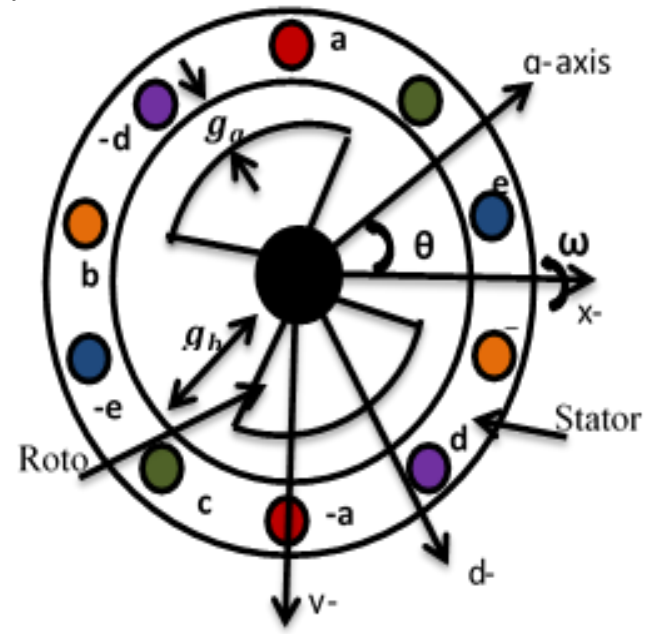

Figure 1 Five-phase synchronous reluctance motor prototype

The voltage equation in the stator is shown below. (Equation 1).

$V_{s}=R_{s} I_{s}+p \lambda_{s}$

The stator flux equation is shown below (Equation 25):

$$
\lambda_{s}=L_{s s} I_{s}
$$

While

$$
\begin{aligned}
I_{s} & =\left[\begin{array}{lllll}
i_{a s} & i_{b s} & i_{c s} & i_{d s} & i_{e s}
\end{array}\right] \\
V_{s} & =\left[\begin{array}{lllll}
v_{a s} & v_{b s} & v_{c s} & v_{d s} & v_{e s}
\end{array}\right] \\
\lambda_{s} & =\left[\begin{array}{lllll}
\lambda_{a s} & \lambda_{b s} & \lambda_{c s} & \lambda_{d s} & \lambda_{e s}
\end{array}\right]
\end{aligned}
$$

And,

$\boldsymbol{R}_{\boldsymbol{s}}=r_{s} \boldsymbol{I}$

$r_{s}$ is the resistance in any stator coil, and $\mathbf{I}$ is a $5 \times 5$ unity matrix, $L_{s s}$ is a $5 \times 5$ inductance matrix that has the following form:

$L_{s s}=\left[\begin{array}{lllll}L_{a a} & L_{a b} & L_{a c} & L_{a d} & L_{a e} \\ L_{b a} & L_{b b} & L_{b c} & L_{b d} & L_{b e} \\ L_{c a} & L_{c b} & L_{c c} & L_{c d} & L_{c e} \\ L_{d a} & L_{d b} & L_{d c} & L_{d d} & L_{d e} \\ L_{e a} & L_{e b} & L_{e c} & L_{e d} & L_{e e}\end{array}\right]$
$V_{s}=R_{s} I_{s}+L_{s s} \frac{d I_{s}}{d t}+\omega_{r m} \frac{d L_{s s}}{d \theta_{r m}} I_{s}$

The transient and steady-state performance of a fivephase SynRM can be described utilizing a specifically defined equation set. If the space harmonics are ignored, there are well-known transformations that can simplify these equations. For example, it is a $5 \times 5$ transformation matrix $\mathrm{T}(\theta)$ to streamline the inductance matrix and to convert the variables from $(a-b-c-d-e)$ reference frame to $(d-q-x-$ $y-n)$ reference frame to get the independence of an inductance $[2,7]$.

So,

$F_{\text {dqxyn }}=\mathrm{T}(\theta) F_{\text {abcde }}$

F may be either stator voltage, current, or flux.

Hence, the concern matrix is:

$\mathrm{T}(\boldsymbol{\theta})=$

$\frac{2}{5}\left[\begin{array}{ccccc}\cos \theta & \cos \left(\theta-\frac{2 \pi}{5}\right) & \cos \left(\theta-\frac{4 \pi}{5}\right) & \cos \left(\theta+\frac{4 \pi}{5}\right) & \cos \left(\theta+\frac{2 \pi}{5}\right) \\ \sin \theta & \sin \left(\theta-\frac{2 \pi}{5}\right) & \sin \left(\theta-\frac{4 \pi}{5}\right) & \sin \left(\theta+\frac{4 \pi}{5}\right) & \sin \left(\theta+\frac{2 \pi}{5}\right) \\ 1 & \cos \frac{2 \pi}{5} & \cos \frac{4 \pi}{5} & \cos \frac{4 \pi}{5} & \cos \frac{2 \pi}{5} \\ 0 & \sin \frac{2 \pi}{5} & \sin \frac{4 \pi}{5} & -\sin \frac{4 \pi}{5} & -\sin \frac{2 \pi}{5} \\ \frac{1}{\sqrt{2}} & \frac{1}{\sqrt{2}} & \frac{1}{\sqrt{2}} & \frac{1}{\sqrt{2}} & \frac{1}{\sqrt{2}}\end{array}\right]$

Through the employing of the transformation Equation 8 in the above matrix equations specified in Equation 1, the voltage equations can be obtained in term of flux linkages in $(\mathrm{d}-\mathrm{g}-\mathrm{x}-\mathrm{y}-\mathrm{n})$ reference frame as following:

$$
\begin{aligned}
& v_{d s}=r_{s} i_{d s}-\omega \lambda_{q s}+\frac{d \lambda_{d s}}{d t} \\
& v_{q s}=r_{s} i_{q s}+\omega \lambda_{d s}+\frac{d \lambda_{q s}}{d t} \\
& v_{x s}=r_{s} i_{x s}+\frac{d \lambda_{x s}}{d t} \\
& v_{y s}=r_{s} i_{y s}+\frac{d \lambda_{y s}}{d t} \\
& v_{n s}=r_{s} i_{n s}+\frac{d \lambda_{n s}}{d t}
\end{aligned}
$$

The $\mathrm{x}, \mathrm{y}$, and $\mathrm{n}$-axes equivalent circuits have zero values, so they do not partake in the torque equation. Thus, the torque production only depends on the $\mathrm{q} \&$ d-axes equivalent circuits.

By applying the previous transformation, the stator inductance will be:

$$
L_{\text {qdxyn }}=\left|\begin{array}{ccccc}
L_{q s} & 0 & 0 & 0 & 0 \\
0 & L_{d s} & 0 & 0 & 0 \\
0 & 0 & L_{l s} & 0 & 0 \\
0 & 0 & 0 & L_{l s} & 0 \\
0 & 0 & 0 & 0 & L_{l s}
\end{array}\right|
$$

Where

$$
L_{q s}=L_{l s}+L_{m q} \quad, \quad L_{d s}=L_{l s}+L_{m d}
$$


$L_{m d}, L_{m q}$ are the mutual inductance of the $\mathrm{q} \& \mathrm{~d}$ axis, and $L_{l s}$ is the stator leakage inductance.

The developed torque equation can be gotten from the magnetic co-energy $W_{c o}$ concept (Equation 11):

$T_{e}=\left(\frac{\partial W_{c o}}{\partial \theta_{r}}\right)$

In a linear magnetic scheme, the co-energy is identical to the stored magnetic energy (Equation 12).

$W_{c o}=\frac{1}{2} I_{S}^{t}\left[L_{s s}\right] I_{S}$

And, $\quad T_{e}=\frac{P_{\text {in }}}{\omega} \frac{P}{2}$

$P_{\text {in }}=\frac{5}{2}\left(L_{m d}-L_{m q}\right) \omega i_{q s} i_{d s}$

Where, $P_{\text {in }}$ is the input power

$\mathrm{P}$ is poles number

$\omega \quad$ is the angular velocity

$\square T_{e}=\frac{5}{2} \frac{P}{2}\left(\lambda_{d s} i_{q s}-\lambda_{q s} i_{d s}\right)$

$=\frac{5}{2} \frac{P}{2}\left(L_{m d}-L_{m q}\right) i_{q s} i_{d s}$

$T_{e}=\mathrm{J} \frac{d \omega}{d t}+\mathrm{B} \omega+T_{L}$

$\square \omega_{m}=\frac{1}{J} \int\left(T_{e}-\mathrm{B} \omega-T_{L}\right)$

The developed torque is dependent on the saliency ratio $\frac{L_{d s}}{L_{q s}}$ which preferred to be large, also the difference $\left(L_{m d}-L_{m q}\right)$ have to be raised to improve the torque density and efficiency of SynRMs.

The essential concept of DTC is that it controls the magnetic flux of the motor stator, as well as its location and amplitude, by employing a specific switching table and choosing the best voltage vector. The stator flux linkage space vector may be determined by the following formula:

$\overrightarrow{\lambda_{s}{ }^{s}}=\int_{0}^{t}\left(\overrightarrow{V_{s}^{s}}-R_{s} \overrightarrow{I_{s}}\right) \mathrm{dt}$

The resulting components from the above vector equation can be analyzed as in the following equations in qdxyn-axis:

$$
\begin{aligned}
& \lambda_{d}=\int_{0}^{t}\left(v_{d}-r_{s} i_{d}\right) \mathrm{dt} \\
& \lambda_{q}=\int_{0}^{t}\left(v_{q}-r_{s} i_{q}\right) \mathrm{dt}
\end{aligned}
$$

So, the equations below can be used to calculate the stator flux linkage magnitude and the electrical flux angle:

$\left|\overrightarrow{\lambda_{s}{ }^{s}}\right|=\sqrt{\lambda_{q}{ }^{2}+\lambda_{d}^{2}}$

And,

$\theta_{s}=\tan ^{-1}\left(\frac{\lambda_{d}}{\lambda_{q}}\right)$

Where

$\theta_{s}$ is stator flux angle between $\lambda_{q}$ and $\lambda_{d}$
The DTC approach can provide instant torque control, resulting in quick torque response and quick reversing operation [17]. The primary benefit of DTC is that it does not require voltage separation, and there is no need for a PWM modulator [18]. The selecting optimal inverter switching vectors for direct and independent control of the flux linkage and the electromagnetic torque. The five-phase SynRM drive has thirty active and two inactive vectors for switching the five-phase SynRM drives [19]. Figure 2 depicts the non-zero vectors. The switching topologies of the inverter switches are represented by the coordinates linked to these vectors, with "one" indicating an ON switch and "zero" indicating an OFF button. Those thirty vectors connect the vertices of three decagons. The distance of the lines is the sole difference between the three decagons. From the lowest to the biggest magnitude, the ratio is $1: 1.618: 1.618^{2}$, correspondingly [20]. Only one switching by one vector to any of two neighboring vectors is required for the greatest decagon, as illustrated in Figure 3 [21]. The ten non-zero vectors were selected as the best switching manners to minimize the five-phase inverter's switching loss. This circle is divided into ten sections by these ten vectors, and the flux position determines the sector number. The following switching vector in any sector is specified by the arrangement of flux and torque errors.

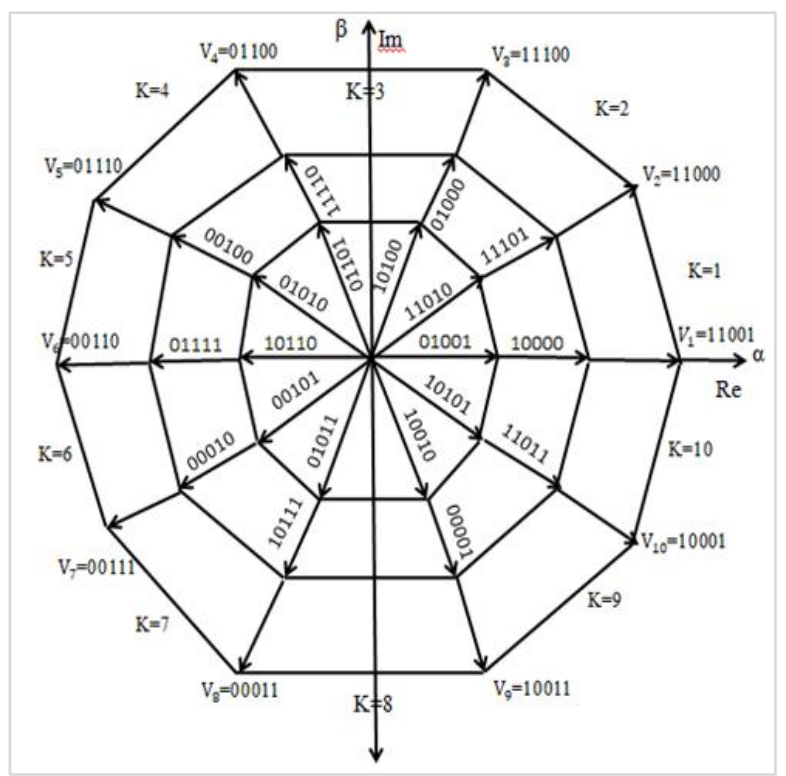

Figure 2 switching vectors of the thirty two space vectors 
The primary goal of employing a switching table in DTC is to compare the measured stator flux and developed electromagnetic torque with their reference values, i.e., $\lambda_{s}^{*}$ and $T_{e}^{*}$, which are the inputs to the two hysteresis controllers [15].

Where,

$\mathrm{d} \lambda=\lambda_{\text {error }}=\left\{\begin{array}{l}1=\mathrm{FR}=\text { Flux Raise } \\ 1=\mathrm{FL}=\text { Flux lessen }\end{array}\right.$

$\mathrm{d} T_{e}=T_{\text {error }}=\left\{\begin{array}{l}1=\mathrm{TN}=\text { Torque Negative } \\ -1=\mathrm{TP}=\text { Torque Positive }\end{array}\right.$

Where, $T_{\text {error }}$ and $\lambda_{\text {error }}$ are the hysteresis controllers outputs torque and flux correspondingly.

Table 1 characterize the best switching table logic look-up table voltage vector for the entire sectors from equations (22) \& (23). So, when the stator flux linkage vector is at the first sector as in Figure 3, and the flux should be raised (FR) while the electromagnetic torque should be positive (TP), the switching voltage vector to be selected is $v_{2}$. Though, when the stator flux linkage must be raised (FR) and the developed torque must be negative
(TN), the vector $v_{10}$ must be chosen. Vector $v_{5}$ will be chosen if the stator flux linkage lessens (FL) and the electric torque will be positive (TP). Vector $v_{7}$ will be chosen if the stator flux linkage lessens (FL) and the electric torque will be negative $(\mathrm{TN})$, as shown in Table 2 below:

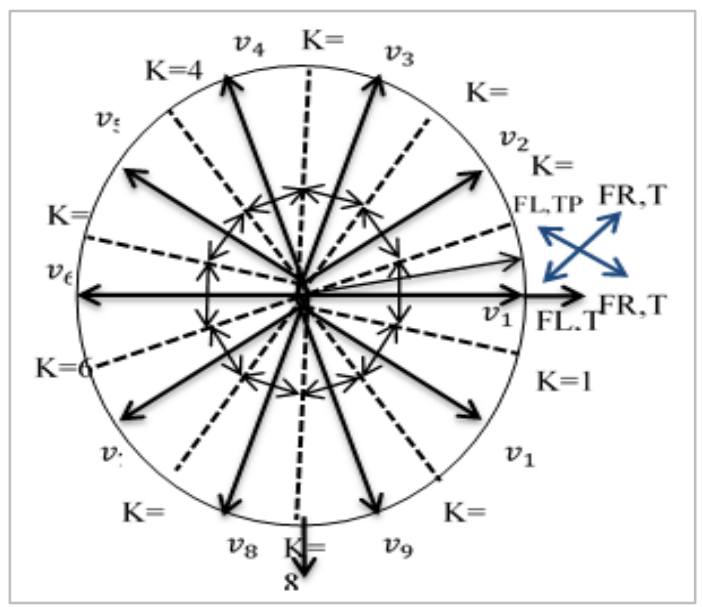

Figure 3 Direct torque control of five-phase SynRM using ten switching vectors

Table 1 optimum look-up table for non-zero vectors

\begin{tabular}{cccccccccccc}
\hline \multicolumn{1}{c}{} & $\boldsymbol{T}_{\text {error }}$ & \multicolumn{1}{c}{ Sectors (k) } & \multicolumn{1}{c}{} \\
\hline & & $\mathbf{1}$ & $\mathbf{2}$ & $\mathbf{3}$ & $\mathbf{4}$ & $\mathbf{5}$ & $\mathbf{6}$ & $\mathbf{7}$ & $\mathbf{8}$ & $\mathbf{9}$ & $\mathbf{1 0}$ \\
\hline 1 & 1 & $v_{2}$ & $v_{3}$ & $v_{4}$ & $v_{5}$ & $v_{6}$ & $v_{7}$ & $v_{8}$ & $v_{9}$ & $v_{10}$ & $v_{1}$ \\
\hline 1 & -1 & $v_{10}$ & $v_{1}$ & $v_{2}$ & $v_{3}$ & $v_{4}$ & $v_{5}$ & $v_{6}$ & $v_{7}$ & $v_{8}$ & $v_{9}$ \\
\hline-1 & 1 & $v_{5}$ & $v_{6}$ & $v_{7}$ & $v_{8}$ & $v_{9}$ & $v_{10}$ & $v_{1}$ & $v_{2}$ & $v_{3}$ & $v_{4}$ \\
\hline-1 & -1 & $v_{7}$ & $v_{8}$ & $v_{9}$ & $v_{10}$ & $v_{1}$ & $v_{2}$ & $v_{3}$ & $v_{4}$ & $v_{5}$ & $v_{6}$ \\
\hline
\end{tabular}

Table 2 The first sector voltage \& flux vector influences

\begin{tabular}{ccc}
\hline $\overrightarrow{\mathbf{v}}_{\mathbf{s}}$ & $\mathbf{T}_{\mathbf{e m}}$ & $\boldsymbol{\lambda}_{\mathbf{s}}$ \\
\hline$v_{2}$ & Positive & Raised \\
\hline$v_{10}$ & Negative & Raised \\
\hline$v_{5}$ & Positive & Lessened \\
\hline$v_{7}$ & Negative & Lessened \\
\hline
\end{tabular}

The previous DTC technique is applied on the fivephase SynRM, modeled as in [22]. It is implemented by using MATLAB/SIMULINK software, illustrated in Figure 4. The stator voltage follows the stator flux if the stator resistance is ignored. As a result, the stator flux vector is being modified over an interval of time by varying the stator voltage from the stator voltage matrix in Equation 1 [23]:

$d \lambda_{s}=V_{s} d t$
Although Equation 24 can compute the stator flux and electromagnetic torque relevant to the stator flux linkage, adjusting the stator flux by changing the stator voltage is more efficient.

From torque Equation 14 can get:

$$
\begin{gathered}
T_{e}=\frac{5}{2} \frac{P}{2}\left(1-\frac{L_{q s}}{L_{d s}}\right) \lambda_{d s} i_{q s} \\
\text { So, } \mathrm{d} T_{e}=\frac{5}{2} \frac{P}{2}\left(1-\frac{L_{q s}}{L_{d s}}\right) \mathrm{d} \lambda_{d s} i_{q s} \\
\text { Let } K_{T}=\frac{P}{2} \frac{5}{2}\left(1-\frac{L_{q s}}{L_{d s}}\right)=\mathrm{constant}
\end{gathered}
$$

By substitute Equation 27 in 26 to produce Equation 28:

$\mathrm{d} T_{e}=K_{T} \mathrm{~d} \lambda_{d s} i_{q s}$ 


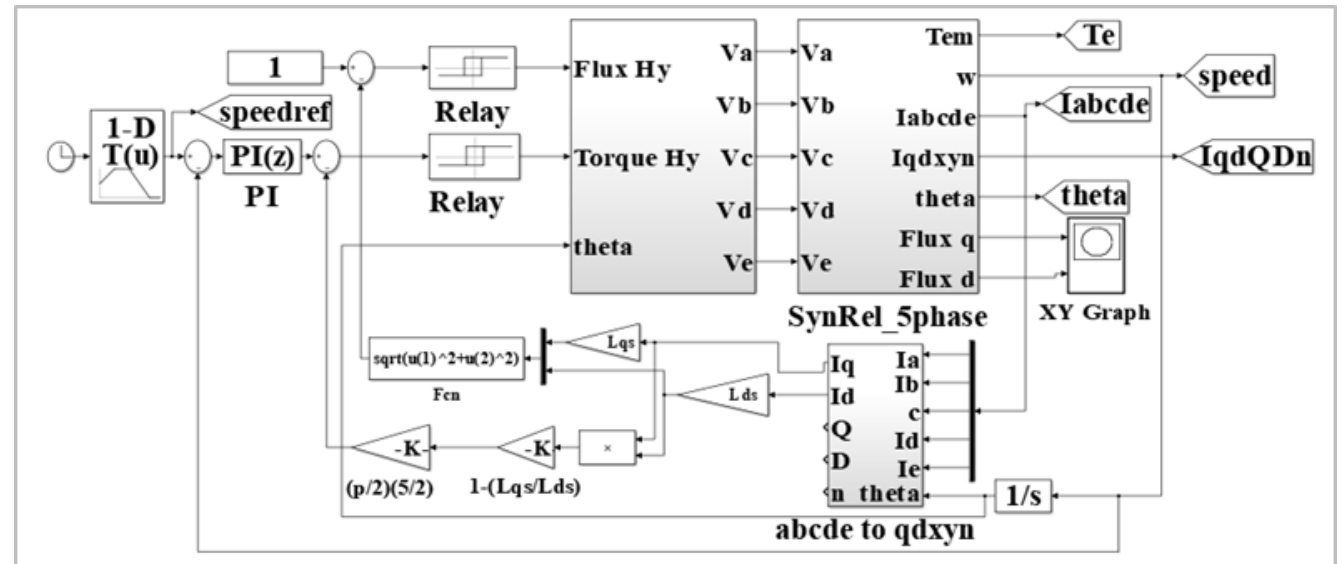

Figure 4 Simulink model OF DTC control for five-phase SynRM

An appropriate look-up table logic inputs in the switching table for the ten non-zero space vectors will be done as shown in Figure 5. Thus, the fivephase voltages are created to supply the five-phase SynRM model in Figure 6; Table 3 illustrates the parameters used in the motor model simulation and are applied in the control scheme simulation on the related motor [24]; the simulation has also been done for several situations.

The three primary goals of this framework are the SynRM model, which uses its speed encoder to estimate the stator flux linkage, actual torque, and actual shaft speed. There are two hysteresis controllers: one for comparing torque command value to real motor value and comparing stator flux command value to real value. The ideal switching logic converts the hysteresis controller's outputs into suitable vector switching signal unit order.
Table 3 SynRM parameters

\begin{tabular}{|c|c|c|}
\hline Parameters & Description & Values \\
\hline$L_{d}$ & $\begin{array}{l}\text { inductance on d- } \\
\text { axis }\end{array}$ & $1.2 \mathrm{H}$ \\
\hline$L_{q}$ & $\begin{array}{l}\text { inductance on q- } \\
\text { axis }\end{array}$ & $0.1 \mathrm{H}$ \\
\hline$V_{\text {rated }}$ & $\begin{array}{l}\text { Voltage in Rated } \\
\text { State }\end{array}$ & $415 \mathrm{~V}$ \\
\hline$R_{S}$ & Stator resistance & 4 \\
\hline $\mathrm{J}$ & Inertia & $\begin{array}{l}0.125 \\
\text { Kg.m2 }\end{array}$ \\
\hline B & Damping & 0.009 \\
\hline $\mathrm{P}$ & Number of Poles & 4 \\
\hline$N_{\text {rated }}$ & Rated speed & 1500 r.p.m \\
\hline$T_{L}$ & Load torque & 40 N.m \\
\hline$P_{\text {out }}$ & Power & 8.4 h.p \\
\hline $\mathrm{F}$ & Frequency & $50 \mathrm{~Hz}$ \\
\hline$f_{S}$ & $\begin{array}{l}\text { Switching } \\
\text { frequency }\end{array}$ & $5 \mathrm{kHz}$ \\
\hline
\end{tabular}

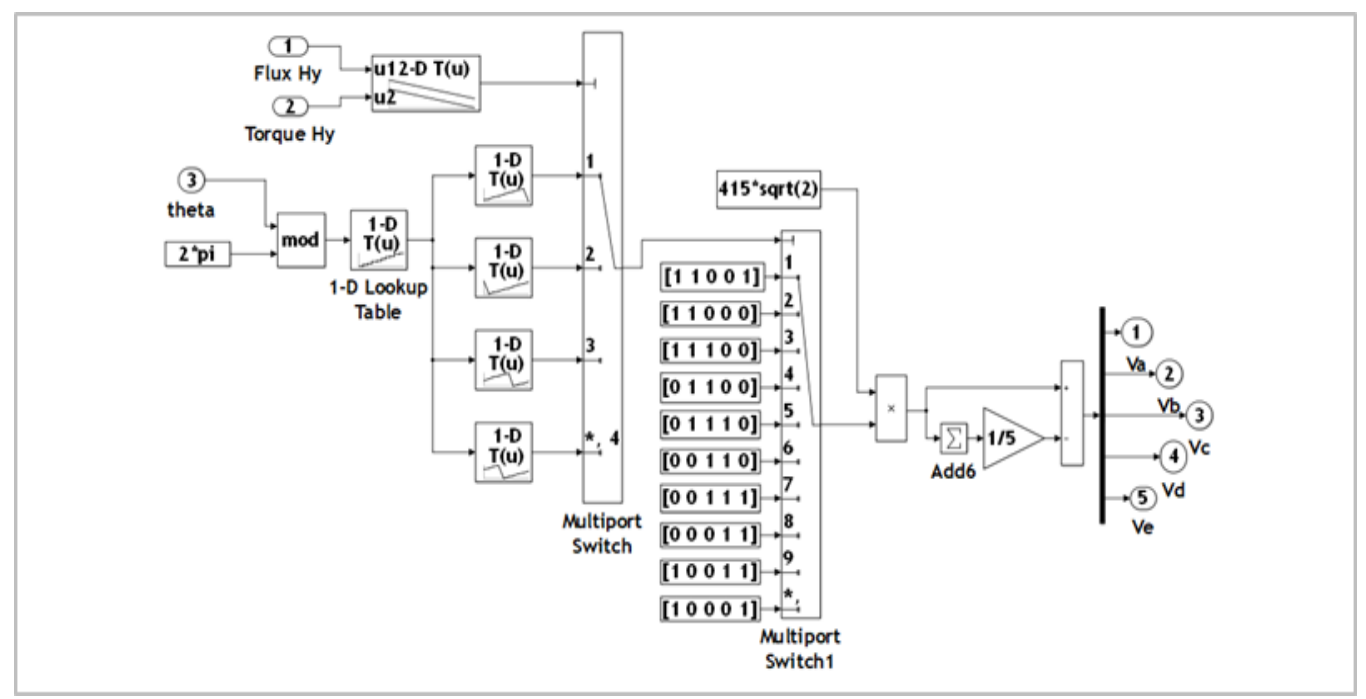

Figure 5 Simulink of look-up table represented the logic switching table 


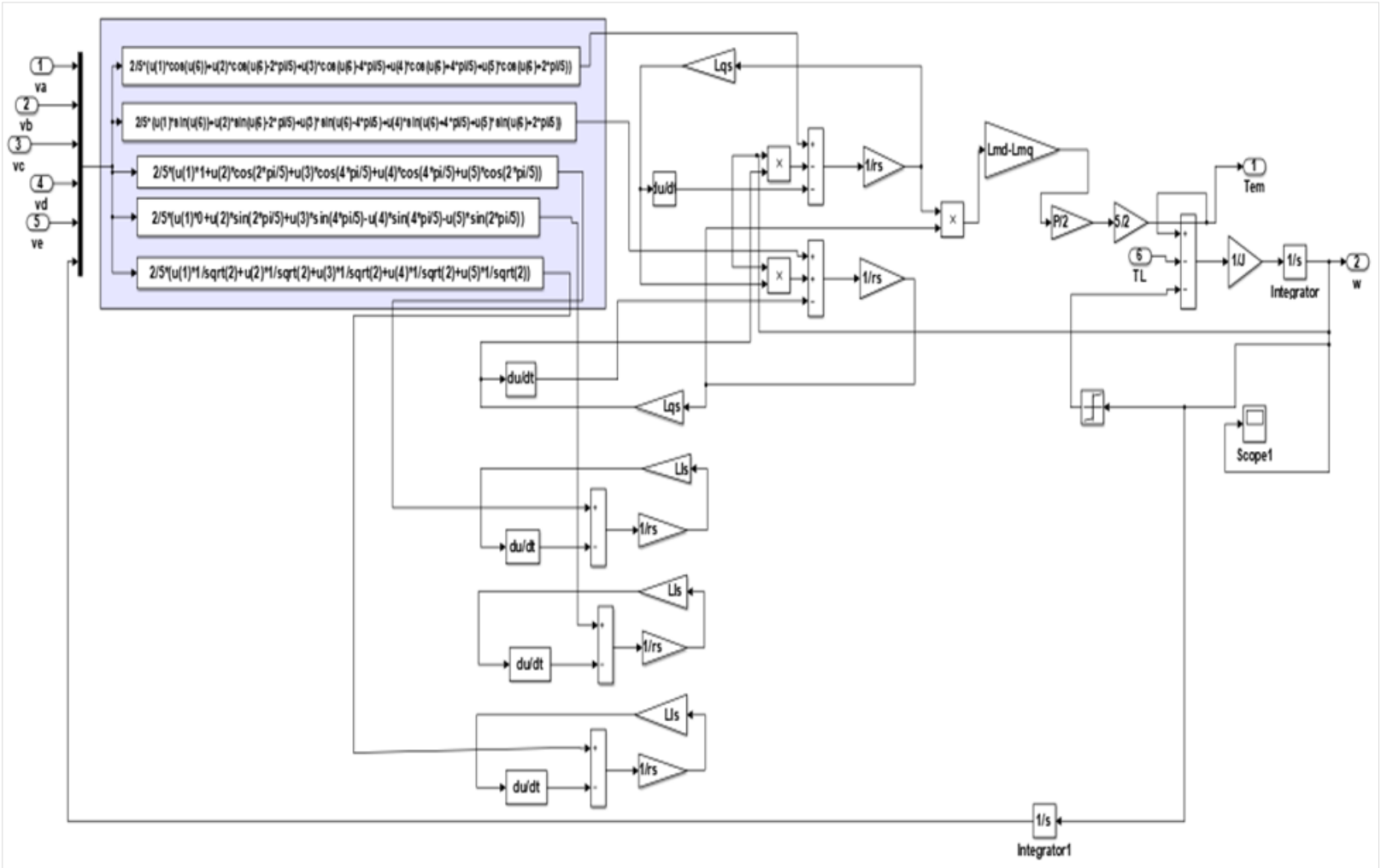

Figure 6 Simulink model of five-phase SynRM

\section{Results}

The dynamic output of the five-phase SynRM is investigated for function with the DTC approach and carried out in Matlab/Simulink software with parameters in Table 3. The sampling time is $5 \mathrm{kHz}$. The excitation of SynRM at starting is done by using the constant value of the reference $d$ - axis stator flux linkage of $1 \mathrm{~Wb}$ and it is held constant at all the simulation time. At $\mathrm{t}=0.3$ sec., the accelerating transient begins from a stop to the synchronous speed of $157 \mathrm{rad} / \mathrm{sec}$ and continues until $\mathrm{t}=0.6 \mathrm{sec}$. to give comparable operation in many speed states as in [15] and [25]. After that, as illustrated in Figure 7, the speed is reversed until $\mathrm{t}=1 \mathrm{sec}$ at $-157 \mathrm{rad} . / \mathrm{sec}$. It's noteworthy that the actual speed matched the reference speed very well because the controllers in the system make the error which is defined as the difference between the actual and reference values of electromagnetic torque and stator flux linkage is approximately equal to zero at steady state but in transent state will be under control as in [18].

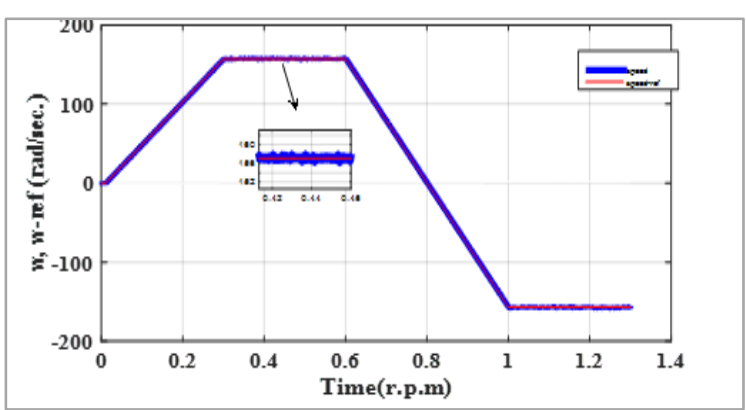

Figure 7 Motor Speed and speed

Figure 8 shows the load torque changing from zero to 20 N.m at $\mathrm{t}=0.01 \mathrm{sec}$. to $\mathrm{t}=0.7 \mathrm{sec}$., then dropping to $20 \mathrm{~N} . \mathrm{m}$ at $\mathrm{t}=1 \mathrm{sec}$. to show the motor performance at various load values. In positive motor operation, the electromagnetic torque begins at $40 \mathrm{~N} . \mathrm{m}$ and settles at $20 \mathrm{~N} . \mathrm{m}$ in regular operation, and $-20 \mathrm{~N} . \mathrm{m}$ in negative motor operation as depicted in Figure 9. 


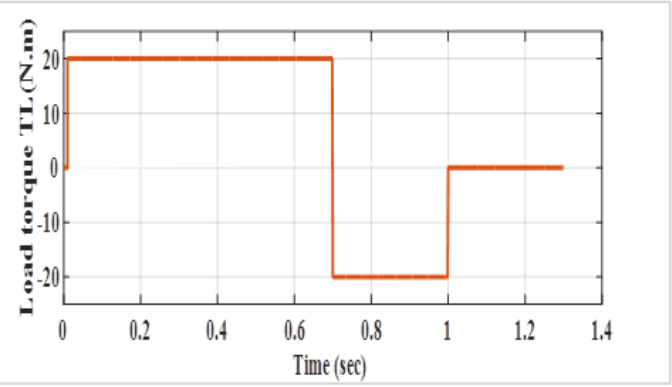

Figure 8 Load torque response

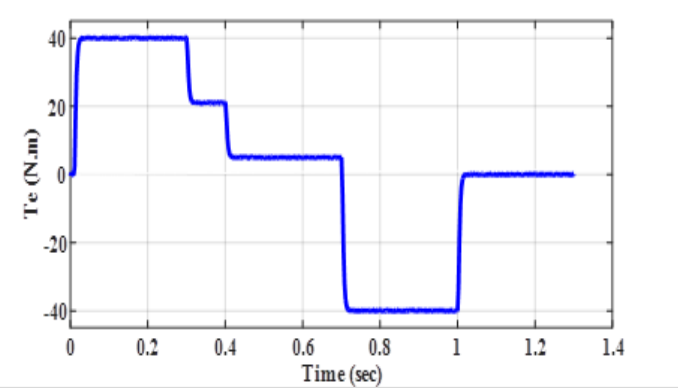

Figure 9 Electromagnetic torque (N.m)

In Figure 10, the rotor position in ( $\mathrm{rad}$ ), namely integrating the speed, and its fluctuation concerning the speed variation. Furthermore, the stator d-axis current and the q-axis current in the synchronously rotating reference frame are varied, as shown in Figure 11 and Figure 12.

The actual five-phase currents i_abcde acquired from the machine are shown in Figure 13, inverse park transformation currents are used to develop these currents, which are inversed according to speed changes. Figure 14 depicts the stator's phase v_a terminal voltages, whereas Figure 15 depicts the line to line voltage. The stator flux variation in all conditions is shown in Figure 16. The d-axis and qaxis fluxes move to indicate that the stator flux is cycling in a predefined pattern, and the suggestions were characteristic.

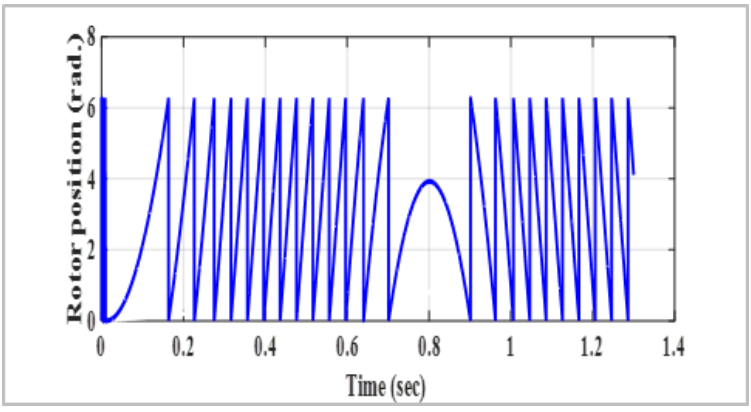

Figure 10 Rotor position (Rad)

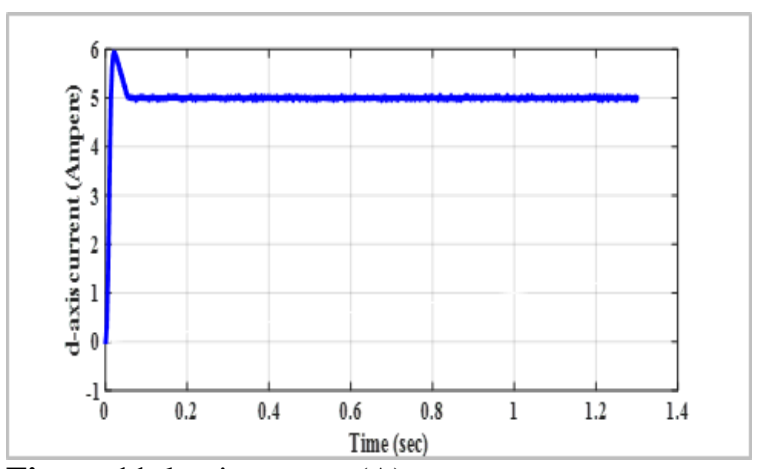

Figure 11 d-axis current $(\mathrm{A})$

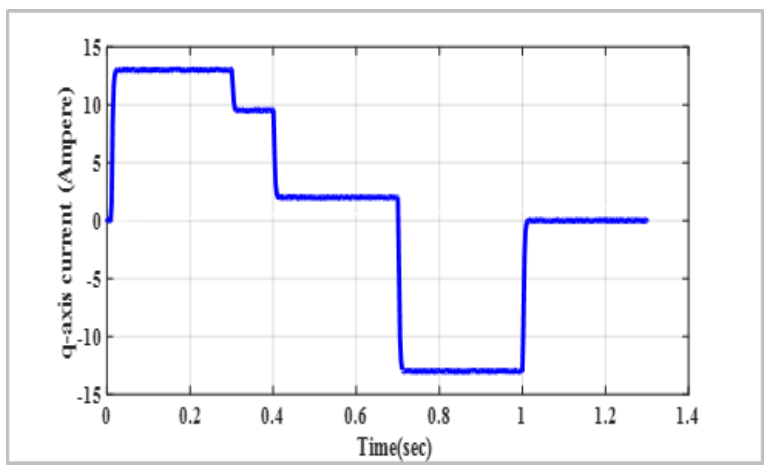

Figure 12 q-axis current (A)

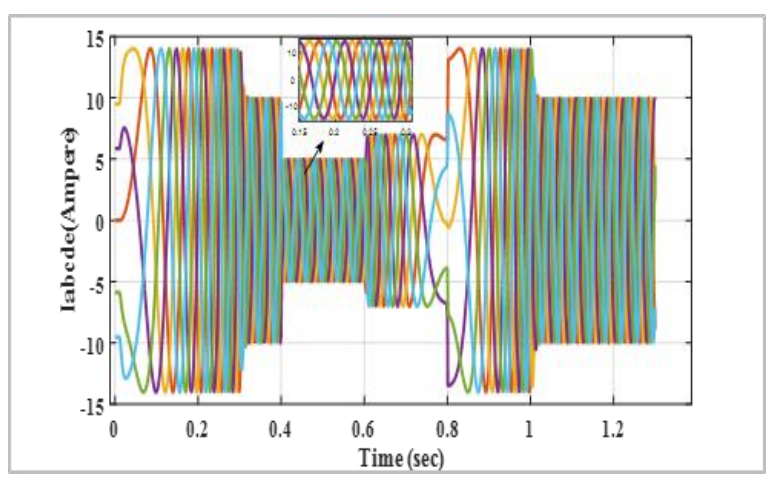

Figure 13 five-phase currents $i_{a b c d e}$

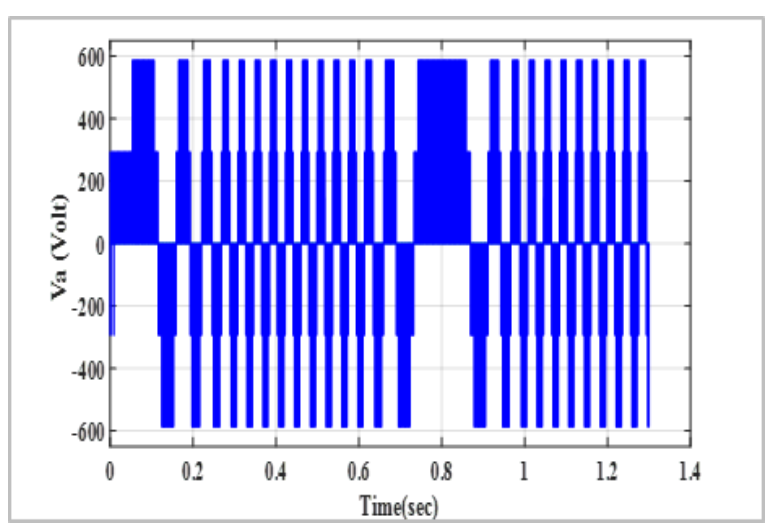

Figure 14 Phase-a voltage $v_{a}(\mathrm{~V})$ 


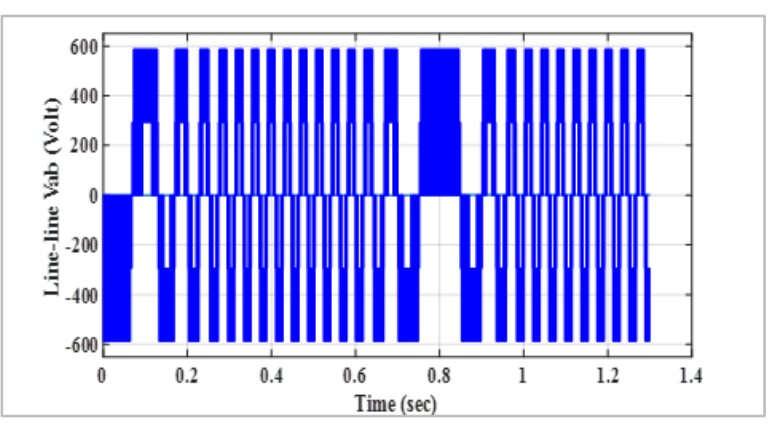

Figure 15 Line to line voltage $v_{a b}(\mathrm{~V})$

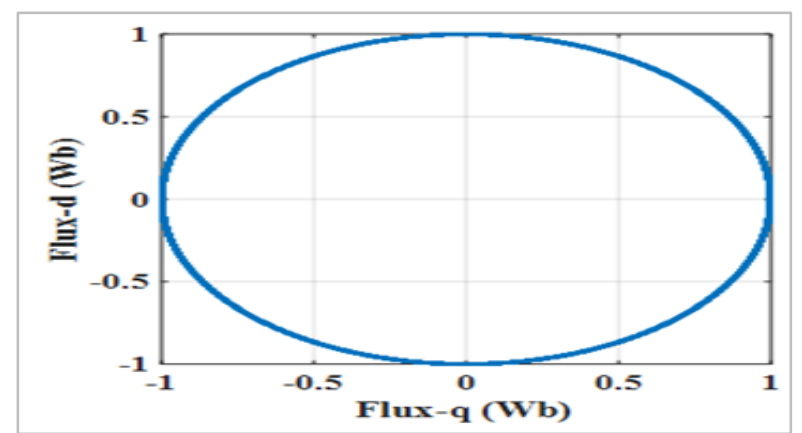

Figure 16 D-q fluxes trajectory

\section{Discussion}

The DTC technique is applied on the five-phase SynRM and is implemented by using MATLAB/SIMULINK software using two hysteresis controllers one for stator flux linkage control and the second for the developed electromagnetic torque that change with stator q-axis current in limited band. Also, there is PI controller for speed with proportional constant Kp equal to 1.652 and integral constant $\mathrm{Ki}$ is equal to 2.35 gotten by try and error. The selection of the optimal switching state in the DTC method is determined by the logic look-up table to get proper order for vector switching status unit. This method reduces the torque ripple, and the speed is well controlled in forward and in reversed operation and didn't affect by the load variation at limited range, with all real values such as rotor position, five-phase current and five-phase voltage follow the reference speed at all conditions. But when the load torque exceeds $200 \%$ of its rated value, the motor goes out of synchronism. This method is considered as a simpler and faster dynamic response than the other well-known methods such as fieldoriented control. A complete list of abbreviations is shown in Appendix I.

\section{Conclusion and future work}

This paper established the Matlab Simulink design of a five-phase SynRM supplied by a five-phase voltage source inverter. The more advantages discovered earlier by the researcher and interested people cause a machine with high phase number vital. Multiphase machines provide several benefits, including excellent reliability when they function continuously even if one of their numerous phases is open or shortcircuited. Therefore, a reduced magnitude of current per phase is a desirable feature in electric vehicles and related technologies. This design is applied to construct five-phase SynRM direct torque control; after that, it is used to implement a specific fivephase DTC-SVM inverter with two hysteresis controllers, each with two-level output for torque comparison and the other for stator flux linkage comparison. As a result, all simulation findings support the created model's validity in all transitory, dynamical, and steady-state response scenarios. Moreover, the prior findings show that the suggested management system is quick, reliable, and resilient below a range of operational situations. Consequently, it can be used in motion control systems with excellent performance and comprehensive range speed control. Application of the DTC method to SynRM lowered the torque fluctuations by \pm 5 and maintained the fast dynamic because it is directly controlled the torque and stator flux linkage. For future studies, this recommended technique can be implemented practically to show the same results experimentally.

\section{Acknowledgment}

None.

\section{Conflicts of interest}

The authors have no conflicts of interest to declare.

\section{References}

[1] Boldea I, Tutelea L. Reluctance electric machines: design and control. CRC Press; 2018.

[2] Shi R, Toliyat HA, El-antably A. A DSP-based direct torque control of five-phase synchronous reluctance motor drive. In sixteenth annual applied power electronics conference and exposition 2001 (pp. 107782). IEEE.

[3] Zhang X, Foo GH, Rahman MF. A robust fieldweakening approach for direct torque and flux controlled reluctance synchronous motors with extended constant power speed region. IEEE Transactions on Industrial Electronics. 2019; 67(3):1813-23.

[4] Ismaeel SM, Allam SM, Rashad EM. Current vector control techniques of five-phase synchronous reluctance motor drive systems. In 21st international middle east power systems conference 2019 (pp. 1180-5). IEEE.

[5] Shi R, Toliyat HA. Vector control of five-phase synchronous reluctance motor with space vector pulse 
width modulation for minimum switching losses. In APEC. In seventeenth annual applied power electronics conference and exposition 2002 (pp. 5763). IEEE

[6] Mun SJ, Cho YH, Lee JH. Optimum design of synchronous reluctance motors based on torque/volume using finite-element method and sequential unconstrained minimization technique. IEEE Transactions on Magnetics. 2008; 44(11):41436.

[7] Toliyat HA, Shi R, Xu H. A DSP-based vector control of five-phase synchronous reluctance motor. In thirtyfifth IAS annual meeting and world conference on industrial applications of electrical energy 2000 (pp. 1759-65). IEEE.

[8] Bilgin B, Jiang JW, Emadi A. Switched reluctance motor drives: fundamentals to applications. CRC Press; 2019.

[9] Chen Q, Yan Y, Xu G, Xu M, Liu G. Principle of torque ripple reduction in synchronous reluctance motors with shifted asymmetrical poles. IEEE Journal of Emerging and Selected Topics in Power Electronics. 2019; 8(3):2611-22.

[10] Chen Q, Shi X, Xu G, Zhao W. Torque calculation of five-phase synchronous reluctance motors with shifted-asymmetrical-salient-poles under saturation condition. CES Transactions on Electrical Machines and Systems. 2020; 4(2):105-13.

[11] Iqbal A. Dynamic performance of a vector-controlled five-phase synchronous reluctance motor drive: an experimental investigation. IET Electric Power Applications. 2008; 2(5):298-305.

[12] Iqbal A, Levi E, Jones M. Simulation studies of current regulated PWM VSI fed multi-phase AC machine drives. In proceedings, student conference on research and development. 2003 (pp. 390-4). IEEE.

[13] Arafat AK, Choi S. Optimal phase advance under fault-tolerant control of a five-phase permanent magnet assisted synchronous reluctance motor. IEEE Transactions on Industrial Electronics. 2017; 65(4):2915-24.

[14] Bonthu SS, Choi S, Baek J. Comparisons of threephase and five-phase permanent magnet assisted synchronous reluctance motors. IET Electric Power Applications. 2016; 10(5):347-55.

[15] Vajsz T, Számel L, Handler Á. An investigation of direct torque control and hysteresis current vector control for motion control synchronous reluctance motor applications. Power Electronics and Drives. 2019; 4(39):115-24.

[16] Abu-rub H, Iqbal A, Guzinski J. High performance control of AC drives with matlab/simulink. John Wiley \& Sons; 2021.
[17] Pellegrino G, Jahns TM, Bianchi N, Soong WL, Cupertino F. The rediscovery of synchronous reluctance and ferrite permanent magnet motors: tutorial course notes. Springer; 2016.

[18] Yousefi-talouki A, Pescetto P, Pellegrino G. Sensorless direct flux vector control of synchronous reluctance motors including standstill, MTPA, and flux weakening. IEEE Transactions on Industry Applications. 2017; 53(4):3598-608.

[19] Chen KY, Xie YL. Reducing harmonics distortion in five-phase VSI using space-vector-based optimal hybrid PWM. IEEE Transactions on Power Electronics. 2016; 32(3):2098-113.

[20] Raja D, Ravi G. Design and implementation of five phase inverter with modified SVPWM switching technique for induction motor drive. In fifth international conference on science technology engineering and mathematics 2019 (pp. 332-7). IEEE.

[21] Rangari SC, Suryawanshi HM, Shah B. Implimentaion of large and medium vectors for SVPWM technique in five phase voltage source inverter. In international conference on intelligent computing and control systems 2017 (pp. 751-6). IEEE.

[22] Ameen NA, Abdulabbas AK, Nekad HJ. Modeling and simulation of five-phase synchronous reluctance motor fed by five-phase inverter. Iraqi Journal for Electrical and Electronic Engineering. 2021; 17(21):58-65.

[23] Zhao G, Liu H, Zhang F, Zhao H, Yuan Y, Jiang Y. Simulation of direct torque control for five-phase PMSM and comparison of optimized vector tables. In China-Russia symposium" coal in the 21 st century: mining, intelligent equipment and environment protection" 2018 (pp. 179-84). Atlantis Press.

[24] Konkani A, Bera R, Paul S. Advances in systems, control and automation. ETAEERE. 2016.

[25] Heidari H, Rassõlkin A, Kallaste A, Vaimann T, Andriushchenko E. Vector control of synchronous reluctance motor with reduced torque ripples. In XI international conference on electrical power drive systems 2020 (pp. 1-5). IEEE.

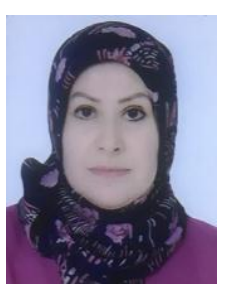

Namariq Abdulameer Ameen, Completed her B.Sc. degree at the faculty of electrical engineering, the University of Basra in 2000. Now receive an M.Sc. degree in the same university. She was working in-state company for fertilizer industry (SCFI) as an electrical engineer for twenty years and she has a piece of good information about most of the Microsoft programs and some of the online programs as well as an in MATLAB/SIMULINK program. Her research interests address all aspects of power electronics, electrical machines, and drives. Also, her English language level is good, and native to the Arabic language. She published some papers since she starts her academic study. Email: nam.almo79@gmail.com 


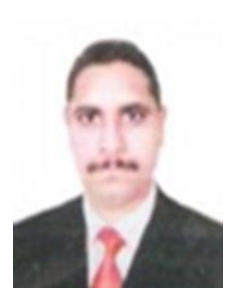

Ali Kadhim Abdulabbas received his B.S., M.S., and Ph.D degrees in Electrical Engineering from the Electrical Engineering Department of the University Basrah in 1999, 2005, and 2012, respectively. He is currently an assistant professor of Electrical Engineering at University of Basrah, Basrah, Iraq. His areas of interest include electrical machines drives and power electronics control.

Email: ali.abdulabbas@uobasrah.edu.iq

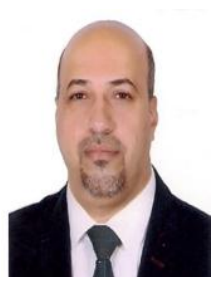

Habeeb Jaber Nekad received his B.S., M.S., and Ph.D degrees in Electrical Engineering from the Electrical Engineering Department of the University Basrah in 1999, 2002, and 2014, respectively. He is currently a lecturer of Electrical Engineering at University of Basrah, Basrah, Iraq. His areas of interest include electrical machines drives and power electronics control.

Email: hjn24177@gmail.com

\begin{tabular}{|c|c|c|}
\hline S. No. & Abbreviation & Description \\
\hline 1 & $\mathrm{AC}$ & Alternating current \\
\hline 2 & $\mathrm{~B}$ & Friction coefficient \\
\hline 3 & BL & Brushless motor \\
\hline 4 & DTC & Direct torque control \\
\hline 5 & FOC & Field oriented control \\
\hline 6 & IM & Induction motor \\
\hline 7 & $\mathrm{~J}$ & Moment of inertia \\
\hline 8 & $\mathrm{~K}$ & Sector number \\
\hline 9 & $L_{l s}$ & Leakage inductance \\
\hline 10 & $L_{s S}$ & Stator inductance matrix \\
\hline 11 & OHPWM & $\begin{array}{l}\text { Optimal hybrid pulse width } \\
\text { modulation }\end{array}$ \\
\hline 12 & $\mathrm{P}$ & Number of poles \\
\hline 13 & PMSM & $\begin{array}{l}\text { Permanent magnet synchronous } \\
\text { motor }\end{array}$ \\
\hline 14 & $P_{\text {in }}$ & Input power \\
\hline 15 & $R_{S}$ & Stator resistance matrix \\
\hline 16 & SPWM & $\begin{array}{lll}\begin{array}{l}\text { Sinsoidal } \\
\text { modulation }\end{array} & \text { pulse } & \text { width } \\
\end{array}$ \\
\hline 17 & SRM & Synchronous reluctance motor \\
\hline 18 & SVM-DTC & Space vector modulation \\
\hline 19 & SVPWM & $\begin{array}{l}\text { Space vector pulse width } \\
\text { modulation }\end{array}$ \\
\hline 20 & SynRM & Synchronous reluctance motor \\
\hline 21 & $\mathrm{~T}(\theta)$ & Transformation matrix \\
\hline 22 & THD & Total harmonic distortion \\
\hline 23 & $T_{L}$ & Load torque \\
\hline 24 & $T_{e}$ & Electromechanical torque \\
\hline 25 & VSI & Voltage source inverter \\
\hline 26 & $g_{a}$ & Air gap in a-axis \\
\hline 27 & $g_{b}$ & Air gap in b-axis \\
\hline 28 & $i_{q s}, i_{d s}, i_{x s}, i_{y s}, i_{n s}$ & Currents in q-d-x-y-n axis \\
\hline 29 & $\begin{array}{l}v_{q s}, v_{d s}, v_{x s}, \quad v_{y s} \\
v_{n s}\end{array}$ & Voltages in q-d-x-y-n axis \\
\hline 30 & $\theta_{m}$ & Mechanical rotor position \\
\hline 31 & $\begin{array}{l}\lambda_{q s}, \quad \lambda_{d s}, \quad \lambda_{x s}, \\
\lambda_{y s}, \lambda_{n s}\end{array}$ & Flux linkages in q-d-x-y-n axis \\
\hline 32 & $\omega_{m}$ & Mechanical angular speed \\
\hline
\end{tabular}

